\title{
Proposal for a Project of Integration of IT Tools With Focus on Planning and Control of Operations on the Shop Floor
}

\author{
Walther Azzolini Junior \\ State University of São Paulo, São Carlos, Brazil \\ José Luís Garcia Hermosila, Antônio Marcos Vitoreli, Rubens Parada Neto \\ University Center of Araraquara, Araraquara, Brazil
}

\begin{abstract}
Manufacturing system, with high level of complexity and with a mix of semi-repetitive and repetitive products, to become productive, should seek the standardization of products and processes to obtain the optimization of use of production resources. However, it is necessary to measure the productivity, so that the system of measurement and control of manufacturing processes are an element critical as to ensure greater visibility of the flow's restrictions, minimized when detected properly. In this case, the automation of factory's measurement process can effectively contribute to ensuring the effectiveness of the function control of a manufacturing system. It is important to consider that the automation of the system of measurement and control of manufacturing processes, of complex environment, is heavily dependent of IT tools applied directly in the interface computational between the operation systems and the corporate systems. This heavy reliance, if exploited technically properly, allows that automation of the system of measurement and control of production makes the access to time real of availability of manufacturing process's data, such as processing time and setup time that it can export to a specialist software in programming production, for example, feasible. In this paper, the automation of the system of measurement and control of production is approached, in order to identify the main possibilities of the design of an information system capable to integrate the flow of information in an environment internal on manufacturing organizations, with emphasis in the digital manufacturing paradigm.
\end{abstract}

Keywords: advanced planning system, operations management, sales and operations planning, shop floor control, supply chain planning

\section{Introduction}

The design and implementation of information technology project in industrial enterprises is currently a great challenge, mainly when considering the number of variables and factors inherent to the process of production.

Walther Azzolini Junior, professor, University of São Paulo (USP) School of Engineering of São Carlos, State University of São Paulo at São Carlos, Brazil.

José Luís Garcia Hermosila, professor, University Center of Araraquara, Araraquara, Brazil.

Antônio Marcos Vitorelli, master in production engineering, University Center of Araraquara, Araraquara, Brazil.

Rubens Parada, master in production engineering, University Center of Araraquara, Araraquara, Brazil.

Correspondence concerning this article should be addressed to Walther Azzolini Junior, University of São Paulo (USP)/School of Engineering of São Carlos, State University of São Paulo at São Carlos, Av. Trabalhador São-carlense, $40013566-590$ São Carlos, SP Brazil. 
Among the main factors, according to the purpose of this paper and according to the literature, the fact is that there are a significant number of computational applications with different functionalities in the market of software development.

However, the selection of software with the purpose of attending to a determined application computational, with the necessary adherence to the operation model of manufacturing enterprises, is not a simple task to accomplish.

The first step, however, is the identification of the levels hierarchical of planning and control of production involved in the management of the operation, as well as the factors that can influence strongly the decision-making process of its modus operandi, which involves the product design, design and operation of the production system, and the organizational infrastructure of manufacturing.

A. C. C. Fleury and M. A. L. Fleury (2000), Olhager and Rudberg (2002), Olhager and Selldin (2007), Thomé (2012), and Olhager (2013) typified the organizational infrastructure of manufacturing from organizational levels: strategic, tactical, and operational, represented in Figure 1:

(1) Strategic level (long-term) - emphasis on the needs of the business/customers - strategic plan and business plan;

(2) Tactical level (mid-term) - aggregate planning from the demand of finished products grouped by product family, master production schedule, and calculation of material needs within the scope of sales and operations planning;

(3) Operational level (short-term) - scheduling of operations, execution, and control (pointing and measurement systems of manufacturing system).

Figure 1 shows the hierarchical levels and Figure 2 shows the main computational tools that can be applied in organizational management process in order to integrate these levels, featuring vertical and horizontal integration of the business.

The description, of the hierarchical levels of an organization with the main features, according to Figure 1, is relevant when the organization wants to design an integration project of flow of information, which should meet the needs of the organization, as well as the agility that the enterprise wants to have in attendance the demand.

In this case, it is relevant to putt the view in evidence that an information system is a set of interrelated components that collect (or retrieve) and process data, transforming them into management information (K. C. Laudon \& J. P. Laudon, 2007). By contrast, the storing and distributing to support the process of decision-making, as well as coordination and the control of business process of an organization must be considered (Elmaraghy, 2005; K. C. Laudon \& J. P. Laudon, 2007).

Thus, such systems or software, according to the scope of an IT project, became part of execution process of activities executed daily in an industrial organization, given the importance that these systems have in a contemporary organization (O'Brien \& Marakas, 2010).

Each hierarchical level, however, can make use of the software with different functionalities, which in turn can have a high level of interdependent among themselves, according to Figure 2.

O'Brien and Marakas (2010) stated that information systems are made up not only of computational systems, but of a number of other elements, such as people, hardware, networks, procedures (work instructions), and policies, among other elements that contribute to the its operation. 


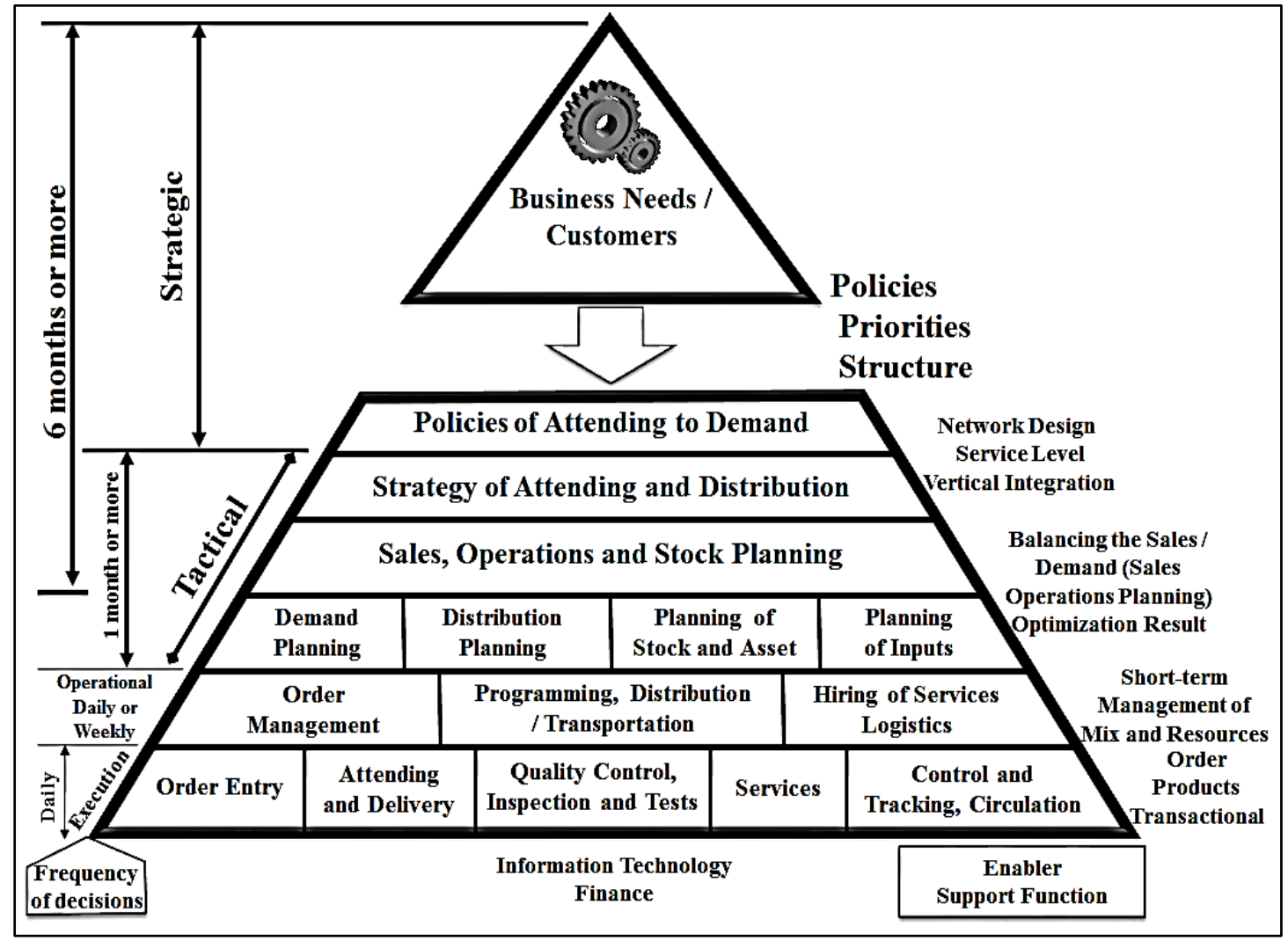

Figure 1. Hierarchical levels. Source: A. C. C. Fleury and M. A. L. Fleury (2000).

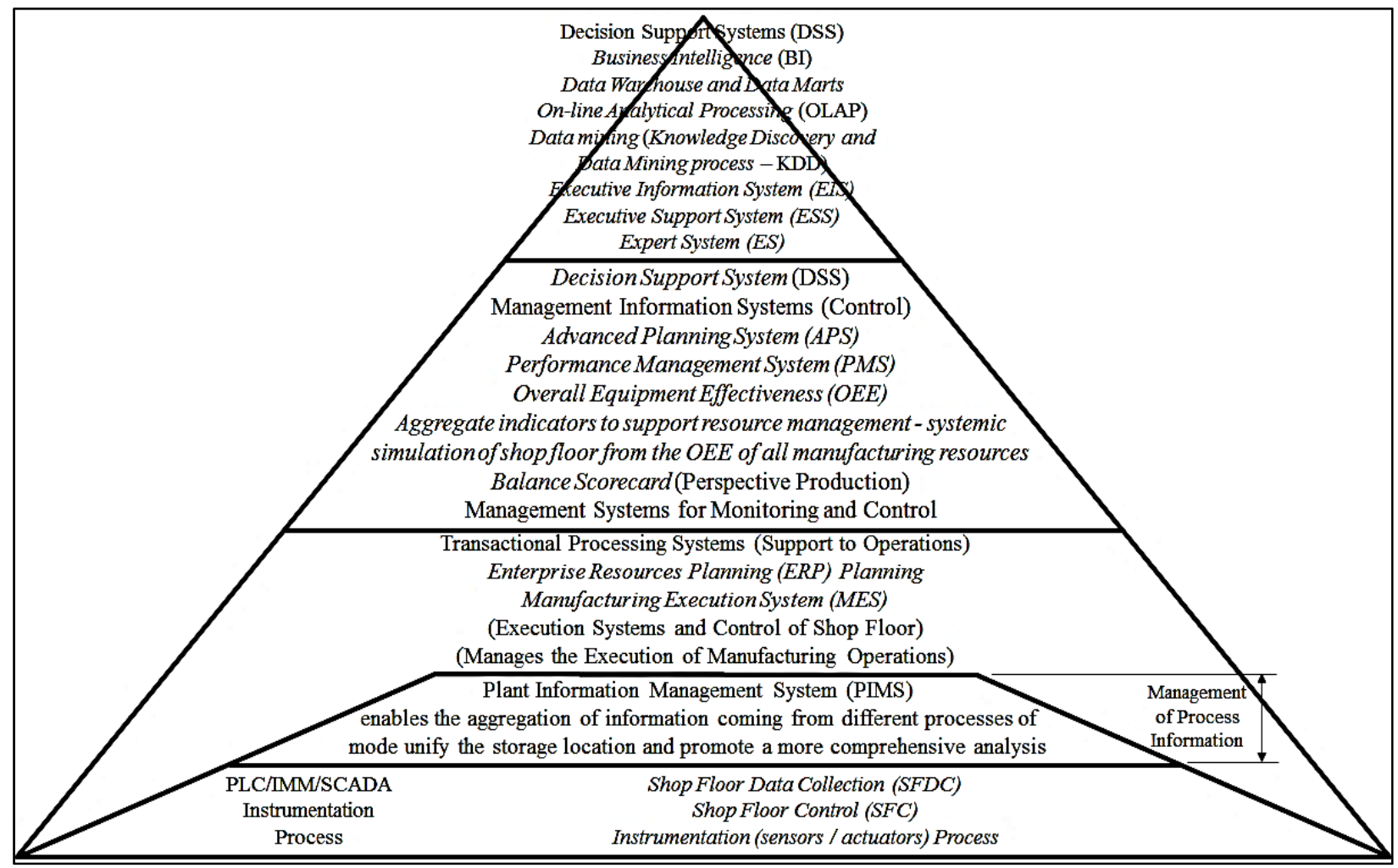

Figure 2. Main computational tools. Source: Authors. 
This paper aims to present the main computational tools mentioned in the literature according to Figure 2 , which, from functionalities specific, can contribute to the process of management of way more integrated of manufacturing system, for example, of organization's business processes and its network within the context of supply chain management.

The paper was dividing into eight sections: introduction; digital manufacturing paradigm; decision support systems with a focus on manufacturing management - manufacturing execution system (MES); plant information management system (PIMS); organizational performance measurement system (OPMS) and performance management system (PMS); technical specifications oriented architecture (SOA), application program interfaces (API), and coupling; reconfigurable manufacturing system (RMS) and cloud computing; and conclusions.

\section{Digital Manufacturing Paradigm}

Azzolini (2004) presented a configuration of the integration of a manufacturing environment with the purpose of supporting the development of the design of new products and components, manufacturing processes, and production scheduling, described from scheme of Figure 3.

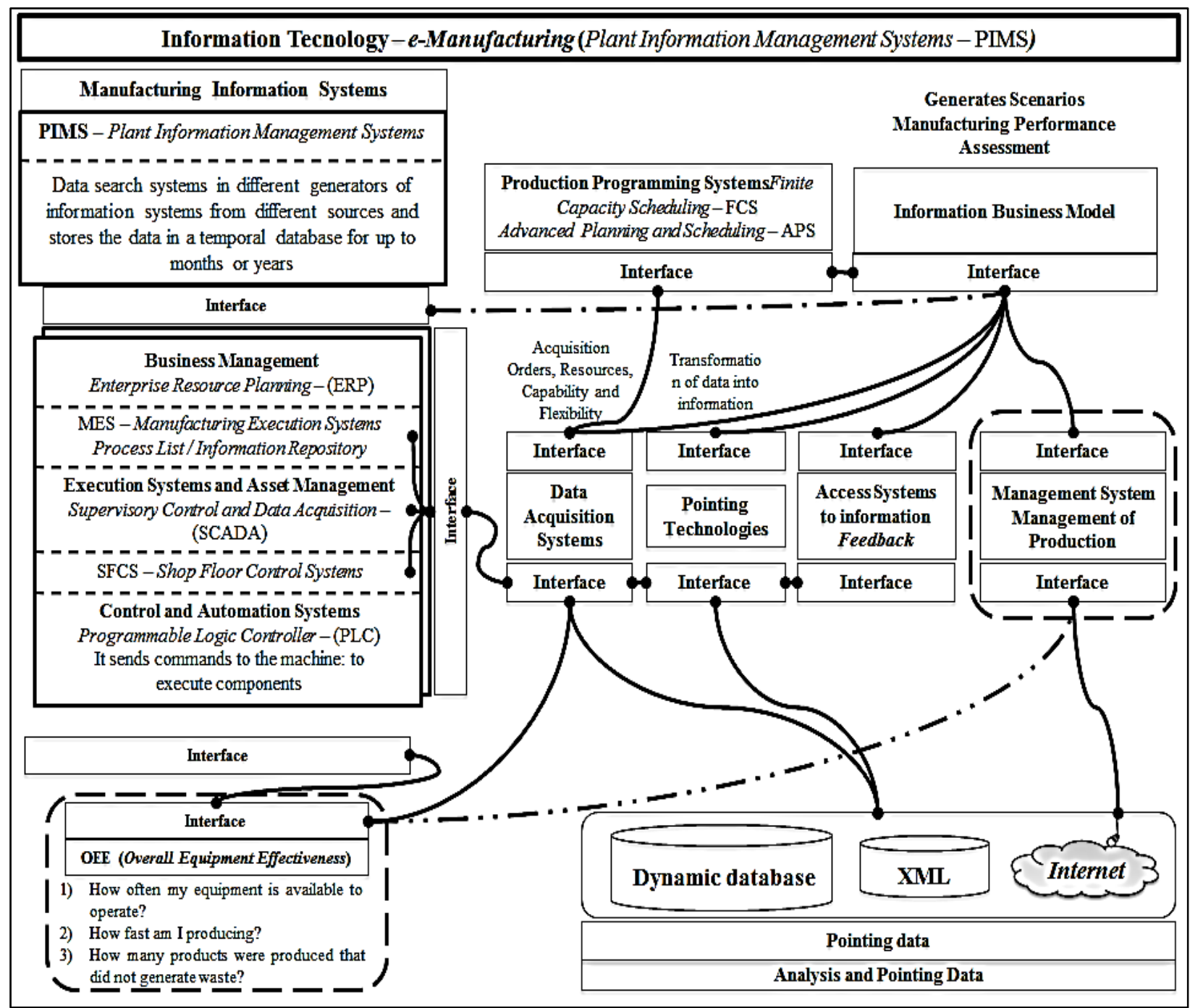

Figure 3. Application of information technology from the functionalities of each category of computational tools. Source: Authors. 
Figure 3 represents the consolidating of data in shop floor, in order to attend the measurement process of the three main indicators of production raised by the authors in literature.

The authors of this paper proposed a preliminary model of the design of IT and the sequence for the design of an information system more robust for application in manufacturing systems with high level of complexity, according to Figure 3.

Galar, Gustafson, Tormos, and Berges (2012) pointed out that in the context actual presented, the greatest challenge is the transformation of data existing in indicators consolidated or aggregate, so that the information for decision makers deems greater performance and visibility of accurate and current mode of operation.

According to the authors' proposal, the function of planning and control of production should have access to information and key data of manufacturing process to the understanding of the production flow, and the definition of manufacturing resources to be used, as well as the availability, so that the system of planning and control of production can identify:

(1) The mix products to be manufactured with demand profile and frequency of request;

(2) Standard time of activities of mounting for the final assembly of the finished product with the devices required for its realization, all pre-defined and designed from the technical specifications for the constructive type of components within the project scope;

(3) Bill of materials-BOM;

(4) Manufacture routes of the components of the product structure;

(5) Determination of the standard operation and standard runtime according to the work instructions.

However, the authors pointed out that the product development engineering can generate technical documents from the use of software CAD and CAM, and technology to convert the data and information of the geometric modeling of product design and its components in the language of manufacturing process.

According to the Figures 2 and 3, the proposal of the authors' papers concerns initially the business management, configured in terms of information systems in three interrelated levels:

(1) Enterprise resource planning.

(2) Execution systems and asset management, which includes:

- Supervisory control and data acquisition-SCADA;

- MES;

- Shop floor control systems-SFCS.

(3) Control and automation systems.

Systems of control with automation, whose data should be processed by the asset management execution systems and consolidated in data acquisition systems to be filtered and distributed by pointing technologies, according to the structure-desired data, must carry out the pointing of manufacturing processes. Whether the access to database of system can be facilitated or not depends on the technical quality of interfaces created. When the problem of interfaces is superadded, the data are easily accessible and available to the users involved in the management process of business model, which together with expert systems in different functionalities, such as finite capacity systems (FCS) and advanced planning and systems (APS).

However, they can make adjustments in production plans, as well as, to do adjustment with the implementing of guidelines or strategies, both emphasizing the integration of guidelines between the business model and manufacturing. 
The integration of product engineering with the process engineering is based on the technology CAD and CAM. According to the scheme proposed by Azzolini (2004), it is from production-scheduling model developed from use of a software APS that the production orders must be released. The releasing of production orders was made according to the task list (production orders) for the execution in shop floor. Already, the monitoring of operation requires to calculate the indicators from data resulting of pointing system in shop floor. The indicators, however, represent the performance of production and the update of these indicators attends the requirements of procedure of calculation of planning capacity (capacity requirements planning - CRP), from manufacturing roadmaps and of the control of fabrication time.

At the time of publishing of the work of Azzolini (2004), the author highlighted the importance of response time of production systems in meeting of the need of finished products of the market. According to the author, it is necessary, however, to use an approach much more effective of problem of utilization of APS software than simply a software of production control. In this case, the database accuracy should make the production plan and control, as the production scheduling, more assertive activities.

With the advancement of information technology, recently, Wu, Rosen, Wang, and Schaefer (2015) pointed out that the use of systems is more technical and of nature less operational. According to the type of computer application applied to manufacturing, occurred initially in the engineering of manufacturing processes, and directly related to design new products, it is always related to the advancement of hardware and software technology. However, such description can be validated with the describing of the stage of development of information technology with the use of CAX software, one of the leading CAD software and then the use of CAM technology, supporting the validation of scheme (Azzolini, 2004).

One has to believe that the technical constraints of technology as the storage of data, interface with enterprise systems, IT project architecture with highly complex interface and processors capable of processing such information flow, were the main problems on designing an IT project with all the desired features.

However, according to the trend of the advance of information technology based on concept: computer integrated and aided design, the IT project changed gradually.

Wu et al. (2015) pointed out that this milestone occurred in the 1960s with the use of systems centralized standalone system (CSS) able to run individually via local installation and the possibility of having a computational tool able to support the design stages from product design, even with the limitations set.

The advancement of technology, resulting among other technical advances, availability of higher processing power computers, though, high financial value acquisition, but able to work at first, 2D drawings, turned out to support the use of the concept CAD and CAM widespread in industries to ensure a significant gain in the process of creating new products engineering.

As for the control of the generated technical documentation and greater accuracy in defining the technical specifications design of products and manufacturing processes, the result was greater precision of the information and technical data product design in order to assist the process engineering in the design of the manufacturing routes and using existing resources in the plant.

Although, even with centralized software configuration of the access and availability of the service on local machines, the fact is that the manufacturing strategy emphasizing the integration has been established and come to rely on the use of CAD software and CAM technology and CNC machines available in market.

Such computing resources, initially designed as tools that facilitate integration, approached with greater emphasis in academia and industry. All the effort, according to Wu et al. (2015), confirmed the emergence of 
systems in distributed access configuration, reality from the 1980s, again changing the landscape of manufacturing strategies and making technically and financially viable integration, based on the chronological development indicated by the authors:

(1) 1980 - more local installation and less client server;

(2) 1990 - fewer local facilities and more client server: use of local networks and the advance of the deployment of corporate enterprise resource planning (ERP) systems with relational database, according to Azzolini and Ferraz (2012);

(3) 2010 - dissemination of use of cloud computing from the 2010 decade with the use of virtual networks with public conception (more strongly the Internet), private or hybrid.

Table 1, according to $\mathrm{Wu}$ et al. (2015), sets out chronologically a process of evolution of manufacturing paradigms from the emergence of mass manufacturing paradigm. As a result, it is a fact, however, that information technology plays a strategic role in the current time from the process.

It describes evolution and acts as a facilitator of the integration process, and consequently reduces the response time to the decision maker as to performance indicators of manufacturing.

Table 1

Evolution of Manufacturing Systems

\begin{tabular}{|c|c|c|c|c|}
\hline $\begin{array}{l}\text { Period } \\
(\text { decade })\end{array}$ & $\begin{array}{l}\text { Paradigms } \\
\text { manufacturing }\end{array}$ & Systems & Configuration & Characteristics \\
\hline Prior to 1900 & Craft manufacturing & Unitary & Centered & High cost of MOB with low production rate. \\
\hline 1900 & Manufacturing mass & Assembly lines & Centered & $\begin{array}{l}\text { Reduces cost MOB \& increases the production } \\
\text { rate. }\end{array}$ \\
\hline 1960 & Lean manufacturing & $\begin{array}{l}\text { Toyota production } \\
\text { system }\end{array}$ & Centered & $\begin{array}{l}\text { Reduces production losses; } \\
\text { Reduces the waiting time; } \\
\text { Reduces defective products; } \\
\text { Continuous improvement. }\end{array}$ \\
\hline 1980 & $\begin{array}{l}\text { Lean and agile } \\
\text { manufacturing }\end{array}$ & $\begin{array}{l}\text { Flexible } \\
\text { manufacturing } \\
\text { systems }\end{array}$ & Centered & $\begin{array}{l}\text { Reduces inventories; } \\
\text { Improves productivity; } \\
\text { Increases the variety of components; } \\
\text { Improves utilization of the machines; } \\
\text { Improves response to engineering changes. }\end{array}$ \\
\hline 1990 & $\begin{array}{l}\text { Responsive } \\
\text { Manufacturing }\end{array}$ & $\begin{array}{l}\text { Reconfigurable } \\
\text { Manufacturing } \\
\text { systems }\end{array}$ & Centered & $\begin{array}{l}\text { Increases responsiveness to market changes; } \\
\text { Reduces the time required for product change; } \\
\text { Reduces the lead time for the introduction of new } \\
\text { manufacturing systems; } \\
\text { Rapid integration or incorporation of new } \\
\text { technologies. }\end{array}$ \\
\hline 2000 & $\begin{array}{l}\text { Digital } \\
\text { manufacturing }\end{array}$ & $\begin{array}{l}\text { Web and } \\
\text { agent-based } \\
\text { manufacturing } \\
\text { systems }\end{array}$ & Distributed & $\begin{array}{l}\text { Improves information sharing; } \\
\text { Improves the reuse of resources; } \\
\text { Improves computational performance; } \\
\text { Remote monitoring and control. }\end{array}$ \\
\hline From 2010 & $\begin{array}{l}\text { Digital } \\
\text { manufacturing }\end{array}$ & $\begin{array}{l}\text { Cloud-based } \\
\text { manufacturing } \\
\text { systems }\end{array}$ & Distributed & $\begin{array}{l}\text { Rapid scalability capacity; } \\
\text { Reduces response time to market; } \\
\text { Reduces costs; } \\
\text { Global computing environment; } \\
\text { Grouped manufacturing resources; } \\
\text { Improves information sharing; } \\
\text { Improves the reuse of resources; } \\
\text { Improves the utilization of the machines. }\end{array}$ \\
\hline
\end{tabular}

Source: Wu et al. (2015). 


\section{Decision Support Systems With a Focus on Manufacturing Management-MES}

According to McClellan (1997) and Laurindo and Mesquita (2000), the MES has emerged in the 1990s in order to fill a communication gap among the planning systems of the relevant manufacturing, the evolution of material requirement planning (MRP), manufacturing resources planning (MRPII), and ERP and the control systems used to run the equipment on the factory floor.

The authors pointed out that a MES is a category of software with an integration of functionality to other online applications pointing to data production operation at the factory and whose purpose is the accumulation of the methods and tools used for monitoring of production (Manufacturing Enterprise Solutions Association [MESA] International, 1994a).

Thus, the MES is initially a consolidation and formalization of the production methods and procedures allowing greater integration of data from all manufacturing processes involved in a more useful and systematic manner.

They also stressed that the MES should be considered as a stage of integration of all activities and it is not in the factory planning level or that it is not a part of the control of the scope of activities. It is possible that components or components of a system must be proactive and online integrated with all other relevant systems to the management of the production process and that they somehow act in the implementation or management of the production flow.

In this case, one MES can be considered as a computational tool imbued to encompass this entire universe of data and information being able to promote a process of high integration synergy among the pairs, which is much greater than the sum of parts of the production system.

It is a fact based on the literature in production management that the MES is not able to provide significant changes in production methods applied on the shop floor and the production control systems (SPC). Also it should not change existing manufacturing processes in a production system, which certainly does not prevent the MES software to be used as a part or component of IT applied to manufacturing, so that your information can support the decision-making process.

Once the manager has had been management tools, it enables to precisely identify which production resources are available, it may at first not be able to increase production, but the information can help you improve priority setting.

Similarly, the time variable and the ability to meet the production orders run in the factory, even if they cannot contribute as a change in the volume of production released by the factory, knowledge of specific skills identified as available which can allow to carry out a plan more realistic or feasible.

MESA International is defined as activities, supported by the MES, related to the different areas, and involved in production management:

(1) Status and allocation of resources;

(2) Details of the operation to support production planning;

(3) List of production tasks;

(4) Control of documents;

(5) Data acquisition and receipt of materials or inputs;

(6) Labor management — provides the workforce status in a given period of time;

(7) Quality management; 
(8) Process management;

(9) Maintenance management;

(10) Traceability of products;

(11) Performance analysis.

Scientific publications, emphasizing applications involving integrated computer systems in the process of production management today, do not explore very different issues on the importance and difficulties related to the use of these tools as shown in the published works of Monks (1987) and Bikfalvi, Erdélyi, Kulcsár, and Tóth (2014).

\section{PIMS}

According to Feijó (2007), in the 1990s, the industry faced the problem of the structure of computer control systems consisting of a concept that gave rise to the formation of islands of automation without the information integration.

Thus, the biggest problem faced by industries in that period in general was the consolidation of data from different manufacturing processes on the shop floor.

In order to assist in tackling the problem of pointing and recording, such data were developed initially in continuous process industries, specifically in the petrochemical sector, a new concept of specific database to control the flow of industrial information, the PIMS, which stands out as an advance of the availability of production data.

Dante (2009) pointed out that the PIMS also is defined in the literature a process information management system and represents a solution designed to fight the problem of lack of accessibility to information.

In addition, according to the author, it is important to consider that the current knowledge of enterprises on the technology of manufacturing process allowed her to move up a level in the pyramid of automation, attending to scope of the Enterprise Production Systems (EPS). It made the emergence of systems PIMS and MES possible.

According to Dante (2009), it is a computer system with the ability of the software to take the logging functionality of the industrial operation data in a consolidated manner, involving all the different plant-processing units kept in a single database. Moreover, stored for a period not limited, that is, for several years, these data are kept available for the different levels already at the planning application-specific format that can add high value for the monitoring and analysis of the production process.

From the functionalities attributed by the authors to PIMS, they claimed that the project should allow the application to provide the user of the following gains:

(1) Consolidation of data in a single database: from the exclusion of single points of information concentrated, which should allow the consolidation of data from different areas and business systems maintained integrated into the same analysis;

(2) Decentralization of access to information: Access to data from different levels of users shall be done in real time;

(3) Collecting and pointing data and information: availability of different types of data and information of the manufacturing process as productivity losses, consumption, process status, unexpected events alerts, performance analysis, process behavior, variability, and downtime; 
(4) Consolidated data allow adding value to information made available for analysis: The system has features capable of performing advanced analysis of the manufacturing process.

It can be deployed in the process of statistical controls, interrelationship data from the used performance indicators, analysis batches, and consequent search for knowledge about the process in order to upgrade the industry knowledge regarding your industrial process.

\section{OPMS and PMS}

Currently the designs of OPMS and PMS have become one of the central issues related to the alignment of business strategies and manufacturing.

A system is a consequence of the other; most methods available in the literature have been developed to meet the measurement and management features; and both systems belong to a single system able to measure and manage the organization's performance.

Fernandes (2004) stated that the OPMS emerged in the 1950s from the use of the Board of Tableau in France, due to the increased dynamism of the world market and the resulting complexity of production systems.

However, several studies in the literature dealing with the computational organizational performance measurement system design address the need of software measurement for this purpose and list all variables and constraints of systemically manufacturing from the manufacturing process data related to manufacturing roadmaps, used manufacturing resource, and process parameters as productive and unproductive times, losses and more.

For this purpose, the central challenge of these works is the development of construction methods of these systems able to consolidate performance indicators previously defined in general indices in order to facilitate analysis of the decision maker from the aggregation of such indicators.

Based on the criteria for consolidation or aggregation of core indicators, literature emphasizes three main methods of measurement and control through performance indicators:

(1) Balance scorecard (BSC): emphasis on resource planning and budget linked to the strategy, that is, the method provides that business strategies must have been defined and should rate the alignment of manufacturing strategies with business strategies from measurement and management of organizational performance, based on the measurement system being built.

(2) The performance prism (TPP): emphasis on the linked strategy for resource planning and budget, i.e., the method provides that strategies are not set, but must be built from the identification of needs, expectations, and contributions of stakeholders in the construction of measurement system.

In addition, the measurement system provides a performance measure of manufacturing that allows identifying how the organization is able to support business strategies.

Or rather, the method should be able to answer the alignment among the strategies which presents deviations that the company will be able to meet or is able to minimize or eliminate restrictions making business strategies feasible within the set time-period to implement them or will not be able to reverse any adverse likely scenario.

(3) Supply chain operations reference (SCOR): the method applied through a diagnosis tool developed from prospects, strategies, and best practices to apply the management technologies in the standard supply chain management by the specialized literature (Siqueira, 2005). 
For this purpose, the 11.0 SCOR tool describes activities carried out under the supply chain management based on macro processes inherent in the planning, supply, production, delivery, and return (Supply-Chain Operations Reference Model, 2013).

Each macro process is divided into sub processes for which performance and statements of best practice attributes defined, allowing comparison and knowledge transfer among supply chains (Supply-Chain Operations Reference Model, 2013).

Conduit, the director of the definition of which measurement indicators should be considered during the design process of OPMS which should consider how central premises the key performance indicators-key performance indicators (KPI) of each internal and external process, based on standards clearly known and control necessary to manage the processes.

Also regarding the definition of the main KPI that should make the measurement system, J. E. G. E. Michel and D. E. Michel (2007) proposed acceptance criteria of the key performance indicators, since the choice of these indicators is based on response given by management regarding the following issues:

(1) The cause and effect relationship between indicators and action plans is clear to the management;

(2) The action plans are considered as a process improvement or a control system in the eyes of decision makers within the hierarchical structure;

(3) The key performance indicators are aligned with the KPI of internal and external stakeholders;

(4) KPIs are used in a fair way in the performance evaluation of employees;

(5) The alignment of business and manufacturing strategies ensures that the changes generated from the strategy adopted in the short-, medium- and long-term are consistent related to the monitoring and prospects for correction of KPI.

The authors emphasized that only after the answers to these questions, can you get the key criteria that must lead to the KPI to support the use of the measurement system. As a management tool can take the company from the process decision-making to become much more precise, the decisions to be taken by the manager within the scope of a continuous improvement system and perspective satisfy the stakeholders.

According to the authors, the key criteria considered are:

(1) The design of a management system with visibility;

(2) The identification of a transparent communication system of the strategies adopted;

(3) The implementation of management monitoring and control systems, such as BSC;

(4) The definition of KPI based on the particularities of the company's organizational structure with emphasis on manufacturing;

(5) The decentralization of management of improvement projects;

(6) The definition of promotion criteria of the people consistent with the KPI;

(7) The management control from the use of the operation information system and integrated performance management;

(8) The definition of fair and consistent criteria in hand resources management work, materials, and manufacturing (equipment).

J. E. G. E. Michel and D. E. Michel (2007) emphasized that all systems and principles should be simple and well maintained to improve the performance measure achieved.

Kumar, Galar, Aditya, Stenström, and Berges-Muro (2013) pointed out that the use of performance indicators in recent years has become the scope of the measurement systems and performance management. 
According to the authors, the performance indicators support the decision makers in process of management of assets or manufacturing resources, especially in the maintenance area.

However, the process of management of assets can present as a result of significant deviations of performance of the operation results expected from the implementation of business strategies, reducing the investment capacity of organization in a given period during the implementation these strategies. In this case, if there is not an immediate action in order to contain or minimize the deviations, the problems caused by deviations can cripple the business economically and financially.

Indicators should therefore focus on the interrelationship of systemically individual indicators as to the shop floor environment, rather than just the asset management itself.

Thus, the use of overall equipment effectiveness (OEE) can be useful both for the use of BSC and the TPP about the prospect of internal business processes related to manufacturing.

According to the considerations of Galar et al. (2012), the biggest problem to be faced in design is the development of performance measurement system.

Galar, Berges, Sandborn, and Kumar (2014) suggested the use of an array of indicators that should be consolidated or aggregated in order to support the decision-making process of both the levels: tactical and strategic.

In one or more indexes that represent(s) the real manufacturing performance and among them, the use of OEE is shown in Figure 3.

The difference, according to Galar et al. (2014), is that the use of the OEE refers to calculation from an inner product, characterized by a binary function.

Whereas the BSC uses a matrix calculation whose size depends on the dimensions related which can make the calculation of the inter-relationship among the dimensions as to the degree of influence among individual dimensions.

However, $\mathrm{Wu}$ et al. (2015) considered that the prospect of SOA architecture can effectively contribute to the advancement of the use of information so as to support greater integration technology.

Because it is based on the principles of distributed computing and uses paradigm of the relationship requested/reply to establish communication between the client systems and the systems that implement the services based on the demands and frequency of using these services.

To $\mathrm{Wu}$ et al. (2015), the principles of distributed computing are part of a strictly technical perspective to meet the demands of utilization of software as service, according to the configuration of service-oriented architecture.

From certain policies and sets of best practice of use technology, the information technology should guarantee access to data in the case of use of data storage virtualization by users, in accordance with Figure 4.

In this case, on one hand, the main purpose of process of task execution is to facilitate the creation of a procedure that must support the execution of task. On the other hand, the process of task execution involves finding, defining, and managing the provider of services.

The supply of services must be so fast and free of operating inconsistencies regarding the availability of services whose main purpose is to facilitate the creation of a process that must support the task of finding, defining, and managing the services provided so fast and free of operating inconsistencies regarding the availability of services. 


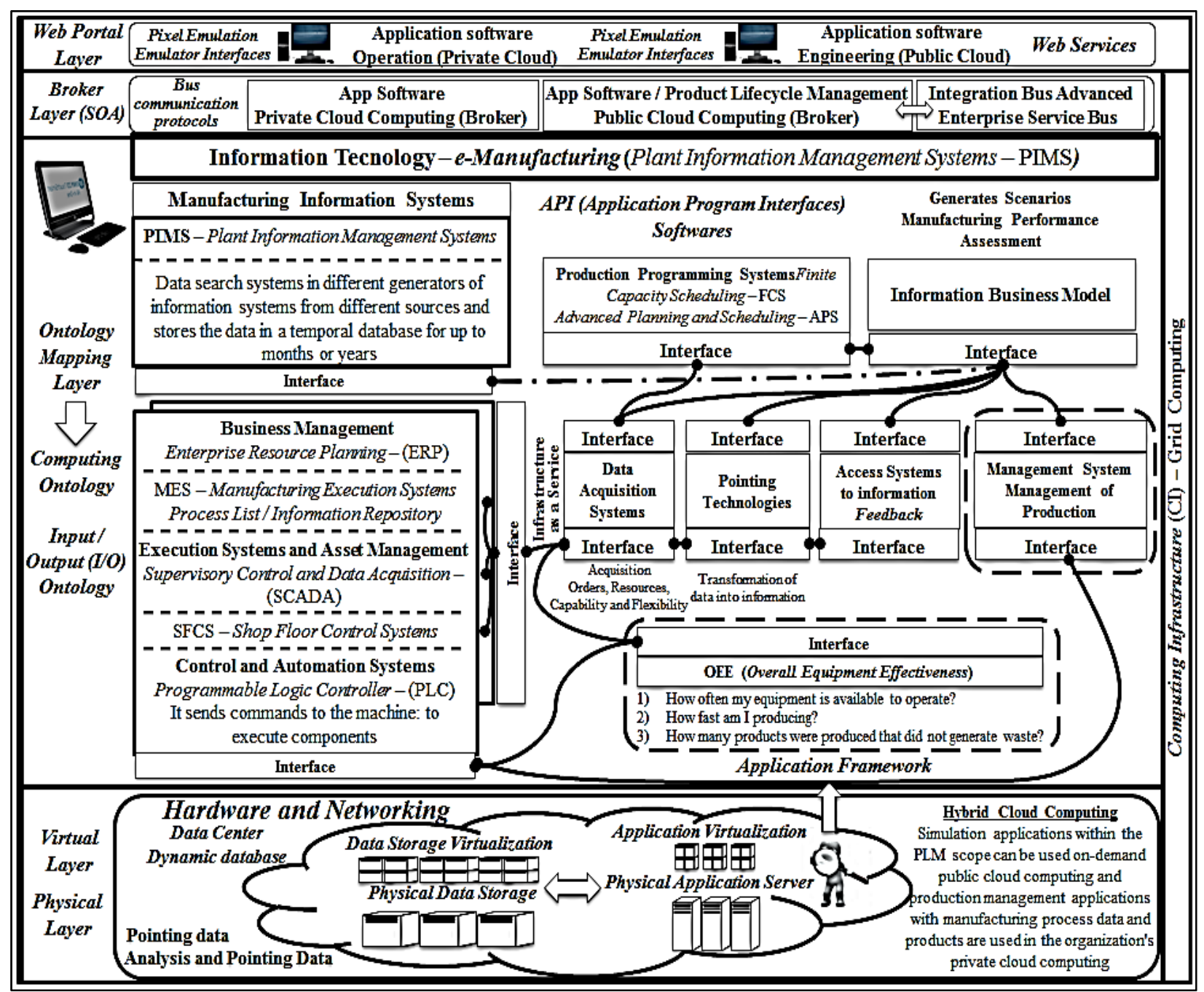

Figure 4. Application of information technology from the features of each category of computational tools. Source: Adapted from Azzolini (2004), MESA International (1994b), and Wu et al. (2015).

Technical SOA, API, and Coupling

\section{Technical SOA}

One of the great advantages of technology with respect to projects conventional of IT, according to Koren et al. (1999), is the operation, so that instead of the access being made through calls direct to the source code of applications, for example, services that should allow access to define protocols that describe how to send and receive messages. In this case, the description in metadata facilitates obtaining of connections with greater accuracy and speed of information flow.

As the computer programming usually the programmers, they make extensive use of language extensible markup language (XML) for describing the data types and structures in service-oriented architecture (SOA) also being a practical, according to $\mathrm{Wu}$ et al. (2015). Web services are typically used from description language (WSDL), also based on XML, which usually describes the services while the protocol SOAP describes the communication protocols, as well as other alternative standards, such as representational state transfer (REST) and web application description language (WADL). 
The SOA architecture is possible only from the availability of data and services described by metadata, which according to the literature must meet the criteria:

(1) The metadata should come in a way that software systems can use the data to dynamically configure the discovery and incorporation of defined services and maintain consistency and integrity;

(2) The metadata should be available from specific formats in a way that the designer of system is able to understand and manage the process with an indicator of cost and reasonable dedication to making operational within a ration cost-benefit acceptable.

According to Figure 3, the broker acts as an intermediary service to be provided and in the case of public, brokers remain the same available on the Internet, while private intermediaries are only accessible to a limited audience, for example, users of a company intranet. Furthermore, the amount of offered information will be decided from the rules and access policies. Table 2 shows a summary of definitions of terms considered in architecture (SOA).

Table 2

Summary of Definitions of Terms Considered in Architecture (SOA) According to Wu et al. (2015)

\begin{tabular}{|c|c|}
\hline Term & Definition/comment \\
\hline Service & $\begin{array}{l}\text { An independent function, stateless accepts one or more requests and returns one or more responses through a } \\
\text { standardized and well-defined interface. Services can also perform discrete parts of a process, such as editing or } \\
\text { process a transaction. Services should not depend on the state of other functions or processes. The technology, } \\
\text { used to provide the service as a programming language, is not be part of the service definition. }\end{array}$ \\
\hline Orchestration & Process sequencing services and provide additional logic for processing data. \\
\hline Stateless & $\begin{array}{l}\text { It does not depend on any pre-existing condition. The services should not depend on conditions of other } \\
\text { services. They receive all the necessary information to provide a consistent response. The purpose of seeking } \\
\text { stateless feature of the services is to enable the service consumer to sequence it or orchestrate them into } \\
\text { multiple streams (sometimes referred to as pipelines) to perform the logic of an application. }\end{array}$ \\
\hline Provider & The feature that the service performs in response to a request from a consumer. \\
\hline Consumer & It asks those who consume the result of a service supplied by a provider. \\
\hline Discovery & $\begin{array}{l}\text { The base of SOA is on the ability to identify services and their characteristics. Consequently, this architecture } \\
\text { relies on a directory that describes what services are available within a domain. }\end{array}$ \\
\hline Binding & $\begin{array}{l}\text { The relationship between the service provider and the consumer should ideally be dynamic established at } \\
\text { run-time through a binding mechanism. }\end{array}$ \\
\hline
\end{tabular}

The expected results are that every SOA is able to group the required functionality from applications built, almost entirely, dedicated to the scope of software services ever designed.

It is considered, according to $\mathrm{Wu}$ et al. (2015) that the larger the pool of features, the lower should be the number of interfaces considered necessary to have any set of features agreed in the contract available. Nazier, Khedr, and Haggag (2013) considered, however, that in these cases more is needed of information, than just data gathering and reporting the outcomes.

However, the literature points out that for very large clusters, it is more difficult to reuse the service offered.

Technically, it must be considered that every interface requires often significant number of processing, which involves performance level change, and, therefore, it is important to take into account the impact on performance or system performance and therefore the granularity of services offered to the user according to their requests.

In the case of manufacturing, the performance of services for architecture depends on the limitations of software in usage, for example, with a limited number of functions only as inventory management and 
production planning a greater number of specific features of the function base requested.

If there is a specific functionality, such as the material requirements planning, the components availability and the covered of components are determined as a requested service.

This practice, according to the literature, allows that the designer of application does not overload when dealing with the complexity of thousands of objects with less granularity.

\section{API}

The use of API aims to use a set of routines and standards set by software for the use of its functionality for applications that do not intend to engage in software implementation details, but only to the use of its features.

For service-oriented architecture in web and the development of framework for this purpose, an API is a set of request defined and response of the messages over a standard HTTP interface, usually in XML or JSON formats.

Any number of connectors as the user itself can transmit the software service request and servers, among others.

This is how an application can interact with a resource knowing the identifier of resource and the required action.

Adopting good practices during the definition of architecture of applications becomes more flexible, unless there is a very high engagement level.

\section{Coupling}

According to the literature, the coupling is a measurement parameter of the degree of dependence among two systems or modules.

This concept is similarly to measure the interdependence in the case of SOA.

The larger the coupling is, the greater the dependency will be between the service and the client that accesses and changes in services will require maintenance in other parts of the system which implies an increased maintenance time and a greater complexity of the system.

Its ramifications are dependents of routines on the need for traceability of lines of code in order to avoid any inconsistency.

However, it is desirable that the codes are as disengaged as possible, so that changes, in a particular service routine, have the least impact on the rest of the codes in a system.

According to $\mathrm{Wu}$ et al. (2015), an example is the existence of two routines performed within the scope of an operation, with slight differences in operation.

If there is any deficiency in the implementation of the codes or if they have been developed separately by different programmers, without the minimum of engagement, when it is necessary to change one of the routines, the other ends up having to be amended following to prevent any inconsistencies, mainly in the execution of routines and consequently inaccuracy of the results generated by them.

However, in order to maintain the processing, which characterizes a type of coupling or dependence of the codes, it is ideal to write the code, so that the level of coupling can be reduced, since it will change the code of the routines in order to remain a single point of maintenance located. In one of the codes or routine without having to make changes in the other when, there are any changes. 
The purpose of minimizing of the level of coupling between the interfaces developed the protocol SOAP and the process management methodology (PMM) that came to support the creation of some coupled codes and a list of guidelines in the selection of the deployment architecture of the related systems and software in an IT project.

\section{RMS and Cloud Computing}

\section{RMS}

According to Wu et al. (2015), the proposal of RMS meets with the proposed use of distributed resources in order to achieve gains of scalability and minimization of cost. The concept fits both manufacturing resources as the information of infrastructure of technology is necessary to achieve this goal, scalability against starting a process more flexible.

Elmaraghy (2005) pointed out that the aspects key of RMS meets this feature, since the proposal seeks to incorporate modularity of the systems.

Modularity must, however, ensure completeness, allowing customization of systems based on demand and availability, and hence the use of resources only when the demands occur.

As described by Azzolini (2004) and $\mathrm{Wu}$ et al. (2015), the fact is that initially the main evolution of manufacturing systems took from the category of centralized manufacturing systems with an emphasis on changes that have occurred from the development of technology, both IT as manufacturing processes. Thus, significant changes have taken place involving the advancement of improvement of the inherent technology to machine tools and consequently the disposition of the machines on the factory floor.

From the design of new layouts and new concepts inherent in the production flow due to computer numerical control (CNC) machines and system Toyota production, the advancement of improvement of the inherent technology to machine tools and consequently the disposition of the machines on the factory floor in turn justified the basis for the design of the concept of distributed resources emphasized today.

Initially these studies prioritized the layout design most flexible as to be able to produce a wider product mix, according to the guidelines set for the manufacturing plant layouts (MPL) and new business models adapted to the impacted by the oil crisis 1973.

The oil crisis 1973 affected the performance of some countries for more than a decade at the expense of the energy matrix based on non-renewable fuels.

$\mathrm{Wu}$ et al. (2015) also emphasized that only from the development and widespread use of Internet technology and computer network that is distributed manufacturing systems (DMS), can it have become increasingly adopted by the industry and manufacturing companies in the area of IT. Such systems, according to the literature, are defined as:

(1) Web based manufacturing systems (WBMS): Fuh and Li (2005) and Wang, Shen, and Lang (2004) defined these manufacturing systems, such as web-based using the IT client/server architecture.

The purpose of using the Internet is to provide a lighter platform to work with teams geographically dispersed, and is able to facilitate access among members of team who share information related to manufacturing via web browser in different locations in the world. The only restriction at first was accessibility, scalability, and the speed of data transfer and information, which it has gradually overcome due to the advancement of technology. 
(2) Agent based manufacturing systems (ABMS): Wang and Shen (2003) and Shen, Hao, Yoon, and Norrie (2006) pointed out that just as in item one, the fact is that with increasing structural and functional complexity of manufacturing systems, there is a strong trend that these systems adopt the model based on web (WBMS). The development of technology began to prioritize the adoption of manufacturing systems based on agents (ABMS) in order to improve performance or communication performance (computational performance-CP).

Manufacturing systems based on agents (ABMS) are to be considered as resources agents, such as manufacturing cells, machine tools, and robots with autonomous operation and endowed with certain level of intelligence based on computational logic and automation, being able to conduct research, build logical thinking, and build a learning process. Monostori, Váncza, and Kumara (2006) stated that from this approach, an agent has been considered as problem-independent issues, able to make decisions interacting with other agents and their environment. In this case, it is more complex, as systems and designed from the most advanced technology within the core of artificial intelligence.

(3) Business Process Management (BPM): practical skills to achieve mutually beneficial results between systems MES and digital manufacturing systems (also called virtual factory), from the design concept of product lifecycle management (PLM) based on the management of the product life cycle. Siemens is a company developing computer application tools with emphasis on this practice.

However, it is a scenario where manufacturing processes require high flexibility, reliability and shorter delivery times, wide combination of variants, and the current reality. So the manufacturing processes have come into coexists with smaller life cycles of products and, therefore they should undergo continuous changes in order to meet the demands of the market with greater accuracy across the constant technological innovations of the manufacturing process and product.

The two major approaches with emphasis on distributed manufacturing that can be considered in this period are manufacturing systems based on usage of web and the use of agents (general resources) that somehow contributed to the manufacturing process in meeting specific demand (web and agent based manufacturing systems-WABMS). Such an advance from the access through client/server and later the protocol of cloud computing, which characterized the development of technology, has enabled the strengthening of the concept of distributed resources as its technical and economic viability.

In this case, having it as one of the pillars, and using the Internet as a public, the general resources distributed more precisely by the latest technology of Web 2.0 and the concept of network use, enabling progress with the concept of digital manufacturing through cloud computing.

\section{Cloud Computing}

According to $\mathrm{Wu}$ et al. (2015), cloud computing began to come reality from the use of application development platforms and servers, storage, and virtual desktops. In the case of cloud computing, it allows that resources are accessed through a Web 2.0 browser or thin client, which in turn, turned out to support the concept of collaboration in business through the concept of distributed resources.

In this case, the use of a variety of networked devices, such as computers, tablets, smartphones, etc. allows you to keep connected at all times with all employees or active participation in specific projects in manufacturing management process. It can not only access information as well as share them, but update them online, according to pre-established rules and procedures for access and interfaces. 
In the case of public cloud computing, according to $\mathrm{Wu}$ et al. (2015), the access of user occurs on demand and resources self provisioned from a catalog of settings predefined, which requires IT infrastructure with higher elasticity and with emphasis on a larger scale in the use of computational resources, i.e., the system must be elastic, so that the access to resource may allow scale-up or scale-down automatically. The advance current of IT technology allows this type of configuration and the emergence of new technologies in this scenery continues to grow. Rapid elasticity on demand implies that the capacity can be increased quickly (scale up) or decreased (down scale) so that the user has the feeling of having infinite resources at any time, often without additional cost to the access and time of use, measured (chargeback) by monitoring and charged according to the service contract. This possibility allows reconfigure resources quickly without the cost of implementation, customization, and investments in hardware and software.

According to the National Institute of Standards and Technology-NIST, cloud computing is a model that aims to allow access to a network, from a certain demand regarding the use of the set of computing resources at this same network. It allows sharing mode configurable, service format, for an example, it can be considered as a given network of servers with storage resources (storage) and applications in the release of shaping services inherent to specific features that the user or users require by running software or software systems. However, $\mathrm{Wu}$ et al. (2015) pointed out that such a model should allow provisioning and releasing the service with minimal management effort or interaction with the service provider, i.e., cloud computing is essentially the notion of using, in anywhere and platform independent, the most varied applications over the Internet as easily to have them installed in local computers.

The main objective is the faster implementation of complex software systems, more flexibility, lower total cost of ownership, and less dependent on IT staff or hardware installed in place of use, as in traditional IT technology. In the case of manufacturing, the viability of the project depends on the size of the company's revenue, geographic distribution of its operations and the industry sector to establish the best IT project strategy. According to research from International Data Corporation (IDC) around two to three, manufacturing companies make use of at least two applications cloud computing currently in the world, implemented through cloud computing, which can be public or private.

\section{Conclusions}

There is a strong trend of large corporations to invest in the use of software specialists in production scheduling, as in the use of simulation software of manufacturing processes, in order to have greater visibility of the real capacity of the plant with perform more appropriated of production plans in execution.

In this context, recent studies found in the literature demonstrated a trend on the development of specialists software in production scheduling, which have the ability to program the supply chain, from the first-tier suppliers to the last level of the customers, to ensure greater visibility and responsiveness in real-time of participants in the chain or network cooperation. The project of IT of a supply chain should be able to meet all, while respecting the particularities of each element of chain in a given moment in time. The result of use of experts software in production scheduling is the mapping of the processes of supply chain that it allows greater visibility of chain links and the identification of its restrictions for the purpose to minimize them or eliminate them to time for the partners.

However, it is up to this new conception of expert systems in production scheduling and the ability to manipulate a significant number of manufacturing process data, respecting all kinds of interrelationships and 
interdependencies as the use of tooling, machines, and various manufacturing resources of a significant number of finished products with their manufacturing routes and BOM by product mix.

This entire process should converge on the need to update the data and information involving product engineering, process engineering, plant management, and management of demand.

The framework that the model of Figure 3 represents, proposed in this work, seeks to consolidate the idea as a preliminary drawing, it is not conclusive, but initial, to define the relationship of the computer systems that a possible proposal for the technology applied in the manufacture information technology project that shall appear depending on system complexity.

\section{References}

Azzolini, W. J. (2004). Tendency of the administration of production evolution process (Tese de doutorado. Universidade de São Paulo_-EESC Escola de Engenharia de São Carlos).

Azzolini, W. J., \& Ferraz, F. J. (2012). Acquiring control-Capacity and priorities management (University of São Paulo, EESC School of Engineering of São Carlos).

Bikfalvi, P., Erdélyi, F., Kulcsár, G., \& Tóth, T. (2014). On some functions of the MES applications supporting production operations management. Applied Information Science, Engineering and Technology. Topics in Intelligent Engineering and Informatics, 7, 103-129.

Dante, J. R. (2009). Qualitative evaluation of an expert system for machine panes identification (PR. Master thesis-Federal Technological University of Paraná, Graduate Program in Mechanical and Materials Engineering, Concentration Area in $\begin{array}{lll}\text { Manufacturing } & \text { Engineering). } & \text { Retrieved }\end{array}$ http://www.ppgem.ct.utfpr.edu.br/dissertacoes/DANTE,\%20Jeferson\%20Roberto.pdf

Elmaraghy, H. A. (2005). Flexible and reconfigurable manufacturing systems paradigms. International Journal of Flexible Manufacturing System, 17(4), 261-276.

Feijó, R. H. B. (2007). A software architecture based on components for industrial information display (Master thesis-Federal University of Rio Grande do Norte, Graduate Program in Electrical Engineering).

Fernandes, B. H. (2004). Competences and organizational performance: An empirical study (Thesis, doctorate in business administration, FEA/USP).

Fleury, A. C. C., \& Fleury, M. T. L. (2000). Business strategies and skills training. São Paulo: Atlas.

Fuh, J. Y., \& Li, W. D. (2005). Advances in collaborative CAD: The-state-of-the art. Journal of Computer-Aided Design, 37(5), 571-581.

Galar, D., Berges, L., Sandborn, P., \& Kumar, U. (2014). The need for aggregated indicators in performance asset management. Eksploatacja i Niezawodnosc-Maintenance and Reliability, 16(1), 120-127.

Galar, D., Gustafson, A., Tormos, B., \& Berges, L. (2012). Maintenance decision making based on different types of data fusion. Eksploatacja i Niezawodnosc-Maintenance and Reliability, 14(2), 135-144.

Koren, Y., Heisel, U., Jovane, F., Moriwaki, T., Pritschow, G., Ulsoy, G., \& Van Brussel, H. (1999). Reconfigurable manufacturing systems. Annals of the CIRP, 48(2), 527-540.

Kumar, U., Galar, D., Aditya, P., Stenström, C., \& Berges-Muro, L. (2013). Maintenance performance metrics: A state-of-the-art review. Journal of Quality in Maintenance Engineering, 19(3), 233-277.

Laudon, K. C., \& Laudon, J. P. (2007). Management information systems (7th ed.). London: Pearson Prentice Hall.

Laurindo, F. J. B., \& Mesquita, M. A. (2000). Material requirements planning: 25 years of history-A review of the past and the future prospect. G\& P Management and Production, 7(3), 320-337.

Mcclellan, M. (1997). Applying manufacturing execution systems. Boca Raton, EUA: CRC Press.

Manufacturing Enterprise Solutions Association (MESA) International. (1994a). The benefits of MES: A report from the field. Pittsburgh: MESA International.

Manufacturing Enterprise Solutions Association (MESA) International. (1994b). MES functionalities and MRP to MES data flow possibilities. Pittsburgh: MESA International.

Michel, J. E. G. E., \& Michel, D. E. (2007). Managers acceptance criteria for performance measurement. Proceedings from EIASM Conference. Nice, France, September.

Monks, J. G. (1987). Production management. São Paulo. McGraw-Hill. 
Monostori, L., Váncza, J., \& Kumara, Sr. (2006). Agent-based systems for manufacturing. Annals of the CIRP, 55(2), 697-720.

Nazier, M. M., Khedr, A., \& Haggag, M. (2013). Business intelligence and its role to enhance corporate performance management. International Journal of Management \& Information Technology, 3(3), 8-15.

O’Brien, J. A., \& Marakas, G. M. (2010). Information systems management. Porto Alegre: Amgh.

Olhager, J. (2013). Evolution of operations planning and control: From production to supply chains. International Journal of Production Research, 51, 23-24.

Olhager, J., \& Rudberg, M. (2002). Linking manufacturing strategy decisions on process choice with manufacturing planning and control systems. International Journal of Production Research, 40(10), 2335-2352.

Olhager, J., \& Selldin, E. (2007). Manufacturing planning and control approaches: Market alignment and performance. International Journal of Production Research, 45(6), 1469-1484.

Shen, W., Hao, Q., Yoon, H. J., \& Norrie, D. H. (2006). Applications of agent-based systems in intelligent manufacturing: An updated review. Advanced Engineering Informatics, 20(4), 415-431.

Siqueira, M. C. (2005). Strategic information management. Rio de Janeiro: Brasport SSC.

Supply-Chain Operations Reference Model [SCOR]. (2013). Supply-chain operations reference model version 11.0. Retrieved from www.supply-chain.org

Thomé, A. M. T. (2012). Sales and operations planning. A research synthesis. International Journal of Production Economics, 138, 1-13.

Wang, L., \& Shen, W. (2003). DPP: An agent-based approach for distributed process planning. Journal of Intelligent Manufacturing, 14(5), 429-439.

Wang, L., Shen, W., \& Lang, S. (2004). Wise-shop floor: A web-based and sensor-driven e-shop floor. ASME Journal of Computing and Information Science in Engineering, 4(1), 56-60.

Wu, D., Rosen, D. W., Wang, L., \& Schaefer, D. (2015). Cloud-based design and manufacturing: A new paradigm in digital manufacturing and design innovation. Computer-Aided Design, 59, 1-14. 